Article

\title{
Evaluation of Multi-Frequency SAR Images for Tropical Land Cover Mapping
}

\author{
Ron Hagensieker * and Björn Waske
}

Institute for Geographical Sciences, Freie Universität Berlin, Malteserstr. 74-100, 12249 Berlin, Germany; bjoern.waske@fu-berlin.de

* Correspondence: ron.hagensieker@fu-berlin.de; Tel.: +40-30-838-58747

Received: 4 December 2017; Accepted: 31 January 2018; Published: 7 February 2018

\begin{abstract}
Earth Observation (EO) data plays a major role in supporting surveying compliance of several multilateral environmental treaties, such as UN-REDD+ (United Nations Reducing Emissions from Deforestation and Degradation). In this context, land cover maps of remote sensing data are the most commonly used EO products and development of adequate classification strategies is an ongoing research topic. However, the availability of meaningful multispectral data sets can be limited due to cloud cover, particularly in the tropics. In such regions, the use of SAR systems (Synthetic Aperture Radar), which are nearly independent form weather conditions, is particularly promising. With an ever-growing number of SAR satellites, as well as the increasing accessibility of SAR data, potentials for multi-frequency remote sensing are becoming numerous. In our study, we evaluate the synergistic contribution of multitemporal L-, C-, and X-band data to tropical land cover mapping. We compare classification outcomes of ALOS-2, RADARSAT-2, and TerraSAR-X datasets for a study site in the Brazilian Amazon using a wrapper approach. After preprocessing and calculation of GLCM texture (Grey Level Co-Occurence), the wrapper utilizes Random Forest classifications to estimate scene importance. Comparing the contribution of different wavelengths, ALOS-2 data perform best in terms of overall classification accuracy, while the classification of TerraSAR-X data yields higher accuracies when compared to the results achieved by RADARSAT-2. Moreover, the wrapper underlines potentials of multi-frequency classification as integration of multi-frequency images is always preferred over multi-temporal, mono-frequent composites. We conclude that, despite distinct advantages of certain sensors, for land cover classification, multi-sensoral integration is beneficial.
\end{abstract}

Keywords: SAR; Amazon; forest; land cover classification

\section{Introduction}

Land Use and Land Cover Change (LUCC) is a main contributor to many acute environmental problems, constituting a loss of biological diversity [1], intensifying the emission of greenhouse gases [2], and affecting the climate [3,4]. It is hence a major driver of global environmental change [5]. Remote sensing is an important tool, enabling detection and quantification of LUCC on large scales and in regular intervals, emphasizing its prevalent role in LUCC sciences [6]. Mapping and monitoring tropical forests seem particularly relevant, e.g., due to their significant carbon store and rich biodiversity, and remote sensing plays a major role for development of a Measurement, Reporting, and Verification system and the implementation of REDD+ (Reducing Emissions from Deforestation and Degradation). Change detection is closely linked to land cover mapping. While methods exist to directly detect gradients within remote sensing data $[7,8]$, many applications are based on the comparison of land cover products at different points in time [9-11].

The Brazilian Amazon is the largest area of tropical rain forest shared by a single country and for many decades it has been particularly affected by LUCC $[10,12,13]$. Therefore, many 
studies use remote sensing data to monitor and quantify different types of land transformation, including deforestation [13,14], conservation [15], or land use intensification [16].

Although multispectral systems are well established and widely used for LUCC based remote sensing [10,17], systems utilizing SAR (Synthetic Aperture Radar) offer additional unique properties. SAR sensors are almost weather-independent, enabling a reliable generation of a time series and thus, a regular monitoring of forest cover. Optical systems are negatively affected by clouds and haze, which occur in particular frequency in tropical regions [18]. Moreover, the number of spaceborne SAR sensors significantly increased during the last several years and further missions will be launched in the future $[19,20]$. With the launch of Sentinel-1 in 2014, the first operational SAR mission is available to offer freely available spaceborne imagery to the public [21,22]. Considering the impact of freely accessible Landsat imagery [23], SAR based remote sensing is expected to become increasingly important over the coming years.

The increasing availability of various SAR sensors also fosters the combination of SAR images acquired at different frequencies. While the SIR-C/X-SAR payload onboard the Endeavour space shuttle provided the first spaceborne, multi-frequency (L-, C-, X-band) SAR datasets [24], various satellite missions are in operation nowadays. Missions such as ALOS-2 (AL2), RADARSAT-2 (RS2), TerraSAR-X (TSX), and the recently launched Sentinel-1 enable a harmonized data acquisition, and thus the generation of multi-frequency data sets, consisting of L-, C, and X-band imagery. Concerning the mapping of LUCC and LULC (Land Use and Land Cover), these wavelengths are often used in different study sites to benefit from the particular backscattering characteristics of various land surfaces (e.g., [25]).

Although X-band data is successfully used for mapping of forests [26], short-wavelength SAR is mainly used for the mapping of low vegetation areas, such as grassland [27], crop types [28], and urban environments $[29,30]$. On the contrary, L-band sensors are predominantly used for mapping forests and densely vegetated environments [31,32], while, given its median wavelength and high availability, C-band data is used for a very wide range of applications. This includes the mapping of boreal and tropcial forests [33-35], and urban areas [29,36]. Additionally, C-band data is widely used for mapping agricultural regions, including crop type mapping and changes in agricultural management [22,37-39]. Still, these examples are not exhaustive. Moreover, the results of many studies prove that the mapping accuracies can be increased when using advanced techniques, e.g., interferometry [26,40], spatial features [30,41], and state-of-the-art machine learning methods [42,43].

To further benefit from the positive capabilities of multiple frequency remote sensing, various studies aggregate datasets from different sensors. Li et al. [44] combine multi-temporal ALOS-PALSAR and RS2 products to improve classification accuracies in a tropical context, stressing the positive properties of L-band over C-band.

However, very few studies to date have focused on an encompassing integration of L-, C-, X-band images in the context of land cover mapping. Particularly in the tropics, Wang et al. [45] observe the backscattering characteristics of different wavelengths with regard to pasture monitoring in a South Australian study site, while Naidoo et al. [46] and Naidoo et al. [47] correlate multi-frequency backscatter with above-ground biomass. Similarly, Baghdadi et al. [48] evaluate the potentials of ALOS-PALSAR (L-Band), ASAR (C-Band), and TSX for sugarcane monitoring. Despite these studies, there is still a lack of research concerning land cover mapping.

The aim of this study is to assess the contribution of multi-temporal, multi-frequency SAR data sets, consisting of AL2, RS2 and TSX images, to LULC mapping in a complex study site in in South Western Pará, in the Brazilian Amazon. The study site is significantly affected by the transformation of forests to pasture, including different types of pasture management and secondary regrowth. We assess the relevance of the different images and potential combinations of data from different sensors through a wrapper approach [49]. This approach enables estimating the importance of different scenes via an iterative generation and evaluation of land cover maps using varying combinations of input scenes. 
We expect the results to support the understanding of the synergetic potentials of different SAR frequencies in the context of tropical mapping, and offer recommendations for future applications.

\section{Study Area}

The study area lies in South Western Pará state, Brazil, in vicinity to the Novo Progresso municipality (Figure 1). The area is a current deforestation frontier and is also affected by post-deforestation dynamics, such as pasture management and secondary regrowth [10,50]. Cattle ranching is the single most dominant form of agricultural land use in the region, despite a slow shift to soy farming, which has recently been affecting farmers in the neighboring, southern state of Mato Grosso [51]. Hence, with regard to land cover mapping, the aim of this study is to evaluate the potentials of different SAR wavelengths for the separation of the region's most relevant land cover types, i.e., Primary Forest, Secondary Regrowth, Clean Pasture, Shrubby Pasture, and Water. Within the context of LUCC and management practices, primary forests are forests that are unaltered and in their natural state. After degradation and deforestation, two relevant types of land use exist within the study area: clean pasture is intensively managed land for cattle ranching often associated with tillage and burning patterns. Shrubby pasture is less maintained, with bushes and signs of secondary succession. Lastly, secondary regrowth describes areas that are not managed anymore and are densely vegetated up to the stage of secondary forests.

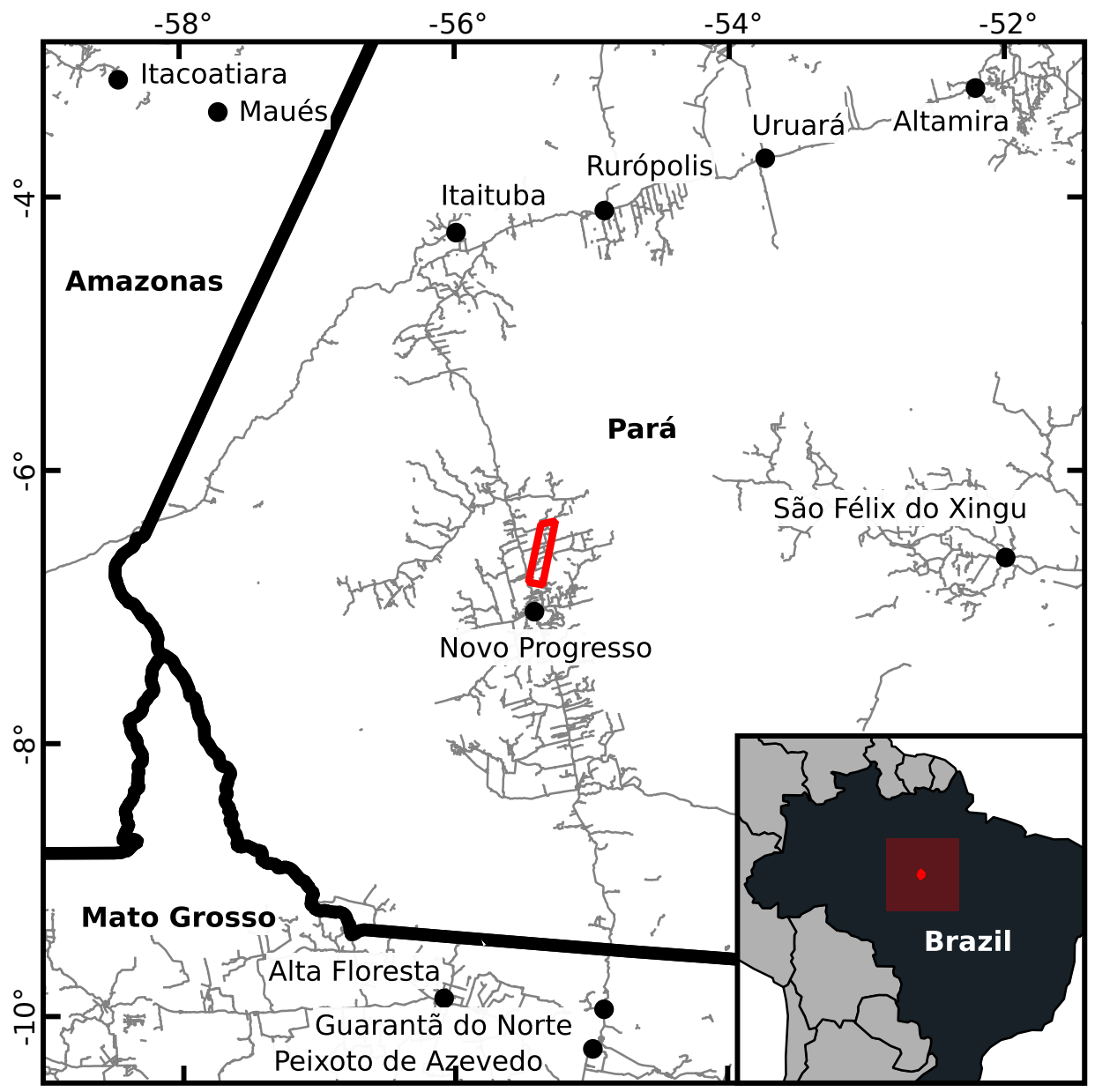

WGS 1984. Administrative data based on Global Administrative Areas and OpenStreetMap.

Figure 1. The study area is defined in an area of severe LULC processes and as the intersection of the available L-, C-, and X-band swaths. 


\section{Data}

\subsection{Remote Sensing Data}

For this study, three multi-temporal data sets of current L-, C-, and X-band sensors are considered (Table 1). Available imagery includes wet, intermediate, and dry season images, corresponding to acquisitions in January, March, and June, respectively.

PALSAR-2 on AL2 is an L-band system operated by the Japan Aerospace Exploration Agency (JAXA) [52]. AL2 works at a wavelength of $24 \mathrm{~cm}$, which marks the longest currently available wavelength from a spaceborne SAR system for scientific purposes. Long wavelength SAR is generally considered the most promising for the mapping of densely vegetated environments, as the signals can penetrate canopy and backscatter can be correlated to above-ground biomass [25]. Data for this study is available in dual, $\mathrm{HH}-\mathrm{HV}$ polarization, and acquired in Fine Beam StripMap mode at $10 \mathrm{~m}$ target resolution after multi-looking.

Operated at C-band, RS2 is a satellite of the Canadian Space Agency (CSA), which offers a wavelength of $5.5 \mathrm{~cm}$ [53]. Studies have shown RS2 and its predecessor, RADARSAT-1, to be applicable for many purposes, but limitations concerning vegetation mapping are well documented [54]. The available data is acquired in Standard Beam mode, at VV-VH polarization, and, after multi-looking, we approximate the recommended operational resolution at $20 \mathrm{~m} \mathrm{[53].}$

TSX is a German SAR satellite mission for scientific and commercial applications. TSX operates at a wavelength of $3.1 \mathrm{~cm}$ [55] and for our study standard StripMap mode data was acquired. While X-band is generally considered less powerful for the mapping of dense vegetation than L-band, due to its high ground resolution and low wavelength TSX could be complementary when used in junction with AL2 data. The recommended nominal resolution of DLR for StripMap TSX imagery is at $5 \mathrm{~m}$, which we approximate through multi-looking.

The subsets in Figure 2 give an overview of the different data sets. As expected, all scenes indicate temporal variability within pasture areas, e.g., due to grazing activities and management practices, while forest areas cause high backscatter. While the rectangular borders along individual pasture areas appear blurred in the RS2 image, edges along different natural objects can be visually recognized due to the high spatial resolution of TSX.

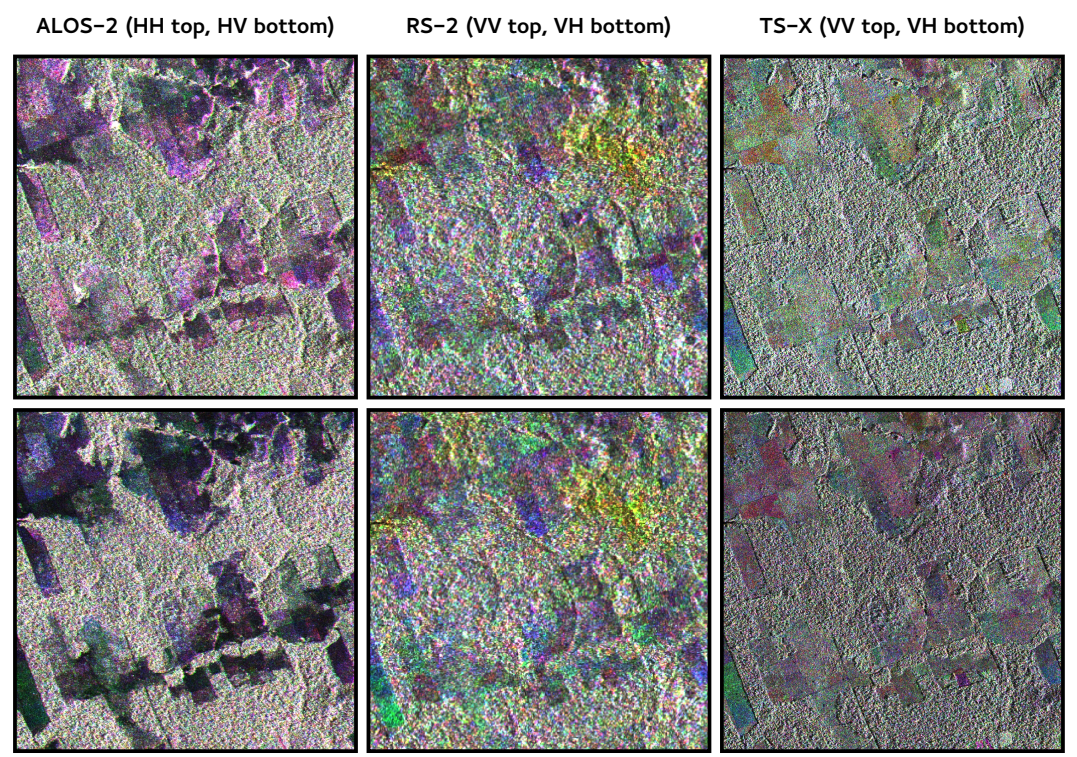

Figure 2. Composites of the available SAR images consisting of January (red), March (green), and June (blue) acquisitions. 
Table 1. SAR images included in wrapper analysis. TerraSAR-X data acquired as StripMap, RADARSAT-2 in Standard Beam mode, and ALOS-2 as Fine Beam StripMap, at $5 \mathrm{~m}, 20 \mathrm{~m}$, and $10 \mathrm{~m}$ targeted ground resolution, respectively.

\begin{tabular}{lr}
\hline Sensor & Date \\
\hline TerraSAR-X & $2015-01-14$ \\
RADARSAT-2 & $2015-01-15$ \\
ALOS-2 & $2015-01-23$ \\
TerraSAR-X & $2015-02-27$ \\
RADARSAT-2 & $2015-03-04$ \\
ALOS-2 & $2015-03-06$ \\
ALOS-2 & $2015-06-07$ \\
RADARSAT-2 & $2015-06-08$ \\
TerraSAR-X & $2015-06-17$ \\
\hline
\end{tabular}

\subsection{Reference Data}

We use TerraClass (Mapeamento do Uso e Cobertura da Terra na Amazônica Legal Brasileira) as reference data. TerraClass is an effort by INPE, the Brazilian National Institute for Space Research, to manually digitize LULC for the entire Legal Amazon [56]. TerraClass addresses areas that are considered deforested according to PRODES [57], and differentiates between 17 LULC classes. PRODES (Programa de Monitoramento do Desflorestamento na Amazônia Legal) is an effort by Brazilian authorities to detect and map deforestation sites based on Landsat and the Moderate Resolution Imaging Spectroradiometer (MODIS) earth observation data, at a minimum mapping unit of $6.5 \mathrm{ha}$. Due to its exhaustive coverage, and the regional expertise of the interpreters, TerraClass products are considered a meaningful foundation to derive large scale, high quality reference data. As TerraClass is built on 2014 data, comparisons with past TerraClass products $(2008,2010,2012)$, show that dynamics can overall be neglected considering the scale of interest. Additionally, our own interpretation using additional RapidEye imagery of 2014 and 2015 furthermore attests its validity. To counteract ambiguities caused by recent deforestation, we use current PRODES data to mask out latest deforestation sites, as deforestation is the most dominant land cover dynamic in the study region [58]. While TerraClass encompasses 17 classes, many of these are either not present in the study area (e.g., mining), or they are considered potentially inseparable using the given classification approach and data sets. Therefore, some classes are semantically aggregated into five target LULC classes Primary Forest, Secondary Regrowth, Clean Pasture, Shrubby Pasture, and Water. Concerning classes of interest within the study area, primary forest is analogous to TerraClass' forest class, secondary regrowth is composed of TerraClass' secondary vegetation and regeneration with pasture classes, clean pasture is a combination of TerraClass' pasture with exposed soil and clean pasture, while shrubby pasture and water are used synonymously. Masked out are the four TerraClass classes encompassing recent deforestation, other areas, utilization, and non observed areas. In summary, reference areas encompass $277.3 \mathrm{~km}^{2}$ for forest, $208.1 \mathrm{~km}^{2}$ for clean pasture, $24.2 \mathrm{~km}^{2}$ for shrubby pasture, $40.9 \mathrm{~km}^{2}$ for secondary vegetation, and $0.4 \mathrm{~km}^{2}$ for water, while $18.5 \mathrm{~km}^{2}$ are masked out. These areas are rasterized into an image of 5 by $5 \mathrm{~m}$ pixel resolution to sample pixels for training and testing. Due to TerraClass being collected based on optical data, which is predominantly available in the dry season between June and September, areas of clean pasture in the reference data can be assumed to be overrepresented due to intra-annual dynamics [59].

\section{Methods}

\subsection{Preprocessing}

All data sets are processed following current standard practices. In a first step, Single Look Complex (SLC) data of all sensors is radiometrically corrected to yield $\gamma^{0}$ terrain-flattened, normalized data [60]. Multi-looking is applied to approximate target resolutions of AL2, RS2, and TSX, 
at $10 \mathrm{~m}, 20 \mathrm{~m}$ and $5 \mathrm{~m}$, respectively. Afterwards, Range-Doppler Terrain-Correction with an $3 \mathrm{~s}$ SRTM is performed. Images are projected into Lambert Azimuthal Equal Area using the SAD69 spheroid, which corresponds to the available TerraClass data. Additionally, images are sampled to exactly meet their intended target resolutions. Following findings by Sarker et al. [54], 10 GLCM texture parameters are derived per polarization and scene. Subsequent filtering (GammaMap) is applied on the $\gamma^{0}$ layers only $[61,62]$. To ensure homogeneity of the resolutions, these steps are performed using windows of approximately $100 \mathrm{~m} \times 100 \mathrm{~m}$ for any sensor, and the number of grey levels is adjusted accordingly. The derived texture parameters are Contrast, Dissimilarity, Homogeneity, Angular Second Moment, Energy, Maximum Probability, Entropy, GLCM Mean, GLCM Variance, and GLCM Correlation. While we acknowledge the existence of correlation and redundancy between different GLCM attributes, our own testing in the past showed these effects to be negligible as long as a capable classifier and a sufficient amount of training data are provided. For this study, we utilize the filtered intensity layers in combination with texture parameters, which were derived from the unfiltered products.

\subsection{Classification}

A random sampling stratified by class is conducted using the reference data set (see Section 3.2). Three thousand samples per class (i.e., Primary Forest, Secondary Regrowth, Clean Pasture, Shrubby Pasture and Water) are selected for classifier training, while the remaining reference data is used for validation. Training samples are drawn point based with a minimal distance of $50 \mathrm{~m}$ to avoid redundancy and reduce the effect of spatial correlation. For testing, locations of all RS2 pixels are considered, and contained TSX as well as AL2 pixels are selected. Polygons are drawn well within the interpreted class borders from the optical and TerraClass reference image. While this might weaken the expressiveness of the classification and its validation for regions at class borders, it ensures that border discrepancies stemming from varying image resolutions are reduced.

Classifications are performed using Random Forest (RF), which is successfully used for various remote sensing applications, including the classification of SAR data [30,43]. A detailed description of RF is given by Breiman [63], and detailed overviews in the context of remote sensing by Belgiu and Drăguț [64], and Waske and Braun [38].

We apply a wrapper approach $[49,65-67]$ with a forward feature search strategy (FFS) to assess the contribution of the different SAR images on the classification accuracy. By sequentially selecting the next most relevant data set, in our study, each SAR acquisition with the corresponding texture layers from both polarizations, the impact of the different data sets on classification accuracy is assessed. A wrapper is based on a classification algorithms (here: RF) and a specified accuracy measure. Let us assume that we have a set of $N$ candidate SAR images $A=\left\{\alpha_{1}, \ldots, \alpha_{N}\right\}$, and a set of selected images $\Omega=\{\}$. A total of $N$ iterations are conducted. At each iteration, unions of $\Omega$ and any element of $A$ get classified and evaluated, resulting in $|A|$ classifications per iteration, with $|A|$ the number of elements in $A$. The candidate image associated with the highest classification accuracy then gets removed from $A$ and integrated into $\Omega$. Afterwards, the next iteration commences. The order of selection refers to the relevance of each data set in terms of classification accuracy.

As an accuracy measure, we choose the area adjusted overall accuracy as discussed by Olofsson et al. [68]. For this measure, area adjusted accuracies are derived from a population error matrix. This approach is particularly useful if class occurrences are uneven. In addition, it can be used to yield confidence intervals for the generated accuracy measures. Entries of the population error matrix are estimated by Equation (1):

$$
p_{i j}=W_{i} \frac{n_{i j}}{n_{i}} .
$$

Contrary to a conventional confusion matrix, $p_{i j}$ are proportion area elements, stemming from the corresponding sample counts $n_{i j}$ of the confusion matrix, and the total area proportion $W_{i}$ of class $i$. Accordingly, the overall accuracy is the sum of the main diagonal of this population error matrix. 


\section{Results}

Table 2 shows the overall accuracies achieved on the individual acquisitions (i.e., iteration 1) and the various combinations, using an RF-based wrapper approach (i.e., iteration 2-9). Confidence intervals of all measures are generated to verify significance.

Table 2. Area adjusted overall accuracy (\%) for each dataset and iteration of the wrapper.

\begin{tabular}{lccccccccc}
\hline & \multicolumn{10}{c}{ Iteration } \\
\hline Scene & $\mathbf{1}$ & $\mathbf{2}$ & $\mathbf{3}$ & $\mathbf{4}$ & $\mathbf{5}$ & $\mathbf{6}$ & $\mathbf{7}$ & $\mathbf{8}$ & $\mathbf{9}$ \\
\hline AL2-Jan & $\mathbf{6 2 . 2 3}$ & & & & & & & & \\
AL2-Mar & 59.60 & 64.05 & 66.26 & 68.07 & 68.54 & 68.81 & $\mathbf{6 9 . 0 2}$ & & \\
AL2-Jun & 60.62 & 64.50 & 66.75 & 68.26 & 68.64 & 68.87 & 68.97 & $\mathbf{6 9 . 2 1}$ & \\
RS2-Jan & 48.93 & 65.56 & $\mathbf{6 7 . 7 9}$ & & & & & & \\
RS2-Mar & 39.15 & 64.62 & 66.84 & $\mathbf{6 8 . 4 0}$ & & & & & \\
RS2-Jun & 46.76 & 65.28 & 67.23 & 68.26 & 68.64 & $\mathbf{6 8 . 8 7}$ & & & \\
TSX-Jan & 56.25 & 65.33 & 66.58 & 68.24 & 68.67 & 68.83 & 69.00 & 69.15 & $\mathbf{6 9 . 2 7}$ \\
TSX-Mar & 57.53 & 65.24 & 66.71 & 68.27 & $\mathbf{6 8 . 6 7}$ & & & & \\
TSX-Jun & 55.51 & $\mathbf{6 5 . 7 8}$ & & & & & & & \\
\hline
\end{tabular}

Comparing all mono-temporal, single-sensor results, i.e., the results achieved in the first wrapper iteration, it can be assessed that the AL2 data yields the highest accuracies, even when the weakest AL2 classification (AL2-Mar, 59.60\%) performs better than the best non-AL2 dataset (TSX-Mar, $57.53 \%)$. As these accuracies are based on Olofsson et al. [68], calculation of standard errors of these accuracies is also feasible. Having used exhaustive TerraClass data as test data, the associated standard errors are all well below $0.001 \%$. This is also emphasized by a visual interpretation of the best classification results, achieved by a single data source (see Figure 3 for reference). It can further be observed that TSX overall outperforms RS2, which is notable given the wavelength and the area of application, and might be a consequence of the favorable spatial resolution of TSX.

The visual interpretation of the results underlines the strong contribution of AL2 data to tropical land cover mapping. Areas are generally correctly classified, and few misclassifications can be observed. Contrary to TSX and AL2, RS2 shows very high confusion not only between Clean Pasture and Shrubby Pasture, as well as Primary Forests and Secondary Vegetation, but additionally between managed and non-managed regions (e.g., Primary Forest and Shrubby Pasture). Accuracies of RS2 are significantly lower when compared to the results achieved by TSX data, and especially RS2-Mar is a negative outlier.

As expected, the classification accuracy increases steadily with increasing number of acquisitions, ranging from $62.23 \%$ up to $69.27 \%$. Comparing the results of iteration 2 , it can be assessed that the combination of the AL2-Jan with additional AL2 images performs worst in terms of accuracy. Despite the documented lower accuracies at iteration 1, RS2 offers results that are comparable to AL2 and TSX in terms of accuracy. Nevertheless, the combination of one AL2 and one TSX scene is most adequate, resulting in the highest gain of 3.55 percentage points using the TSX-Jun image. The dataset is complemented by RS2 images in the third iteration. However, from iteration three onwards, and including scenes from all three sensors, the positive impact of additional scenes on the accuracy is significantly reduced. The visual assessment of the classification results (Figure 4) underlines these findings. The numeration in Figure 4 indicates the corresponding iteration of the wrapper approach and the added scene. For example, after selecting AL2-Jan at the first iteration, the TSX acquisition from June is selected at iteration two. Classification of these two scenes results in an area adjusted OA of $65.78 \%$. Although all maps show the general structures of the classified area, some maps are noisy even in homogeneous areas. Borders along the edges appear blurred and hard to identify. This drawback is significantly reduced by combining different data sets. 

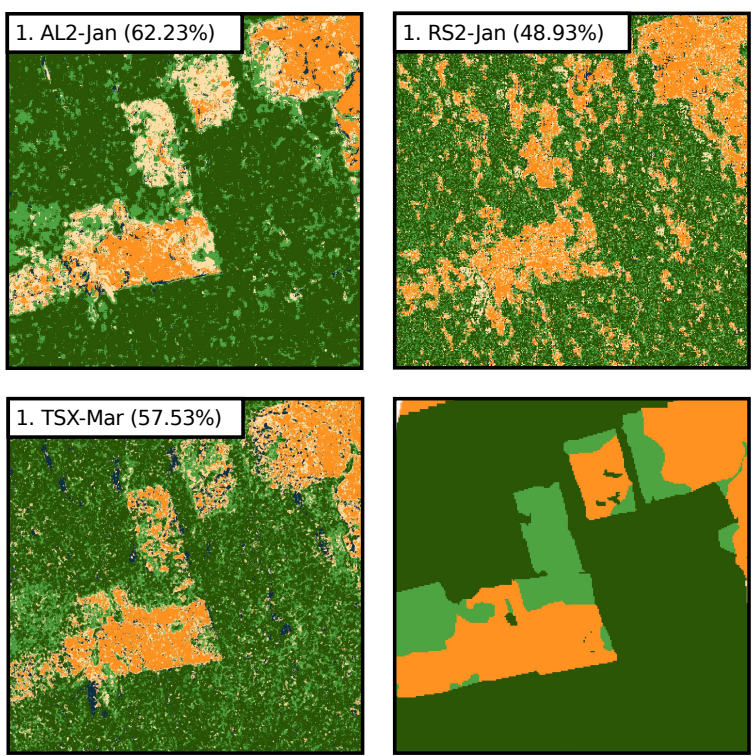

Primary Forest $\square$ Shrubby Pastur
Secondary Vegetation $\square$ Clean Pasture

Figure 3. Comparison of the single scene mapping capabilities. Scenes are shown that yield the highest overall accuracy per sensor. The bottom right shows the TerraClass reference image.
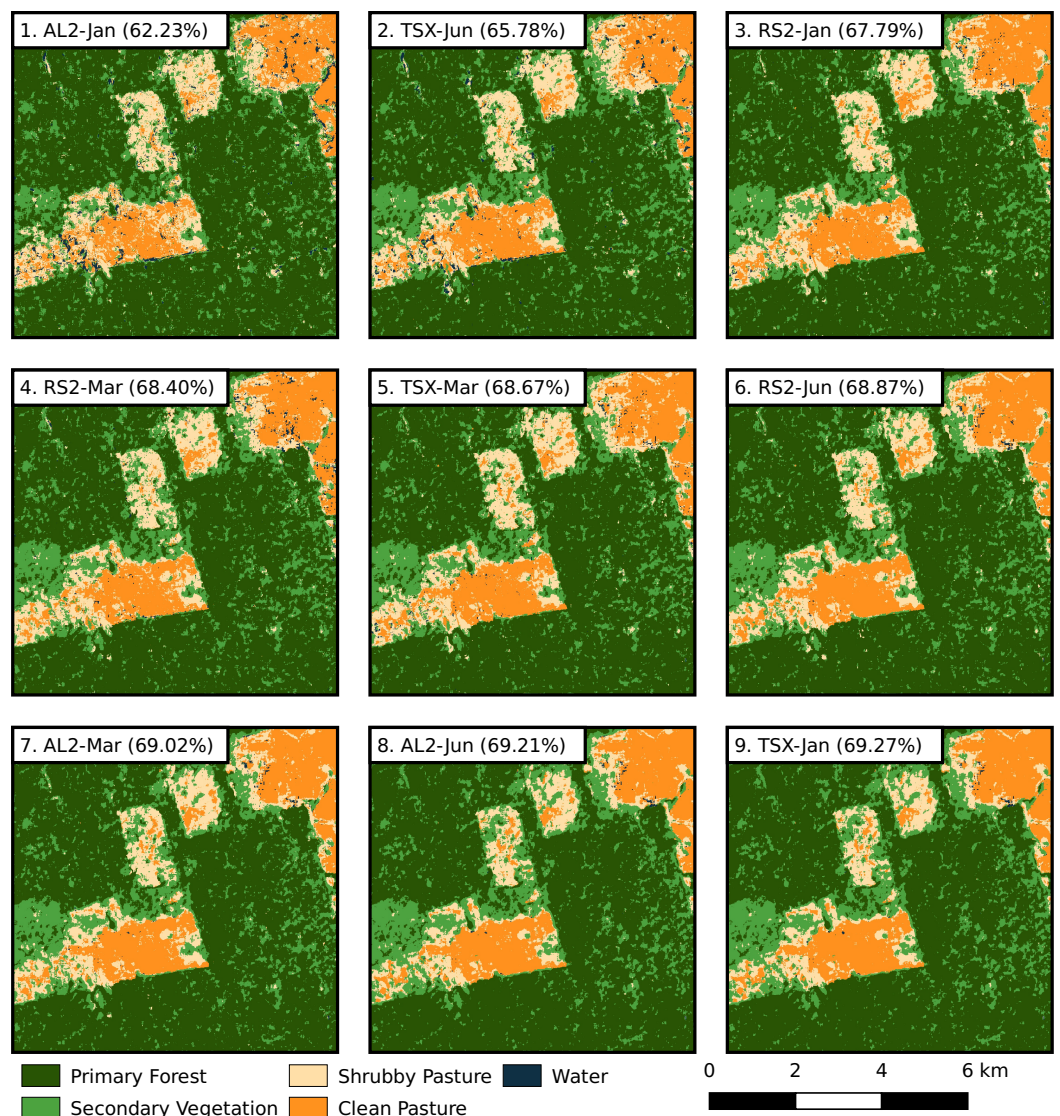

Figure 4. Subsets of the classification result, achieved after each iteration of the wrapper. The classification is based on all specified data sets, e.g., the RS2-Jan is selected as the third data set and added to the AL2-Jan and TSX-Jun, which have been selected beforehand. The classification of these three datasets results in an accuracy of $67.79 \%$. 
The contribution of the SAR data to the tropical LULC mapping is also underlined by an analysis of the Producer and User Accuracies (PA, UA). Figure 5 shows the gains in area adjusted UA's and PA's achieved by the RF-wrapper approach. Correlating with the receding increase of overall accuracy, UA's and PA's mark high gains for the first additional scenes, before the gains are approaching zero. The figure shows that the PA of clean pasture benefits overall very well from the inclusion of further scenes in addition to the original AL2-Jan scene. Figure 6 compares the final multi-temporal, multi-frequency land cover product with the reference data derived by TerraClass. The corresponding confusion matrix is shown in Table 3.
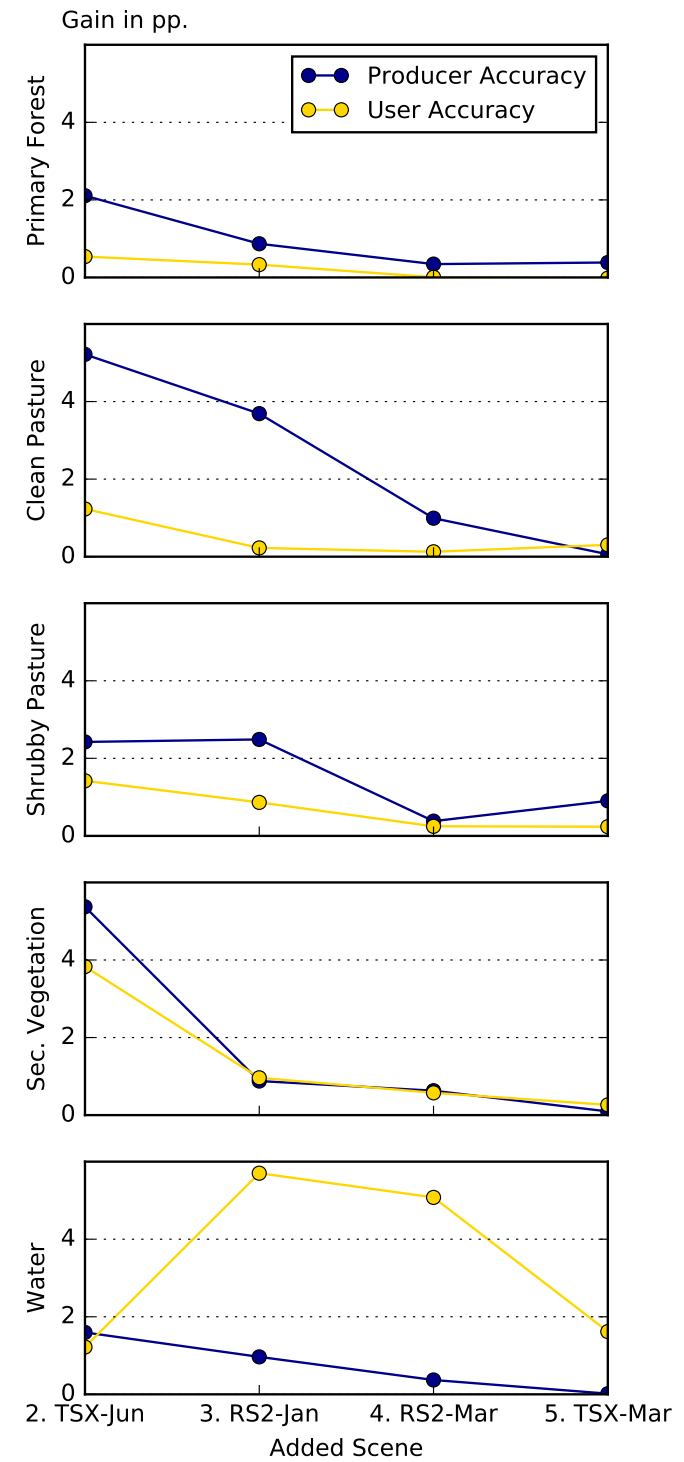

Figure 5. Gains in User and Producer Accuracy for wrapper iterations 2-5.

As noted previously, the highest confusion exists between Primary Forest and Secondary Vegetation, as well as between Clean Pasture and Shrubby Pasture. Notably, many Clean Pasture regions are misclassified as Shrubby Pasture, while Shrubby Pasture is generally not labeled Clean Pasture. Additionally, many Primary Forests are classified as Secondary Vegetation and vice versa. While confusion exists between Secondary Vegetation and Shrubby Pasture, it is not as prevalent. 


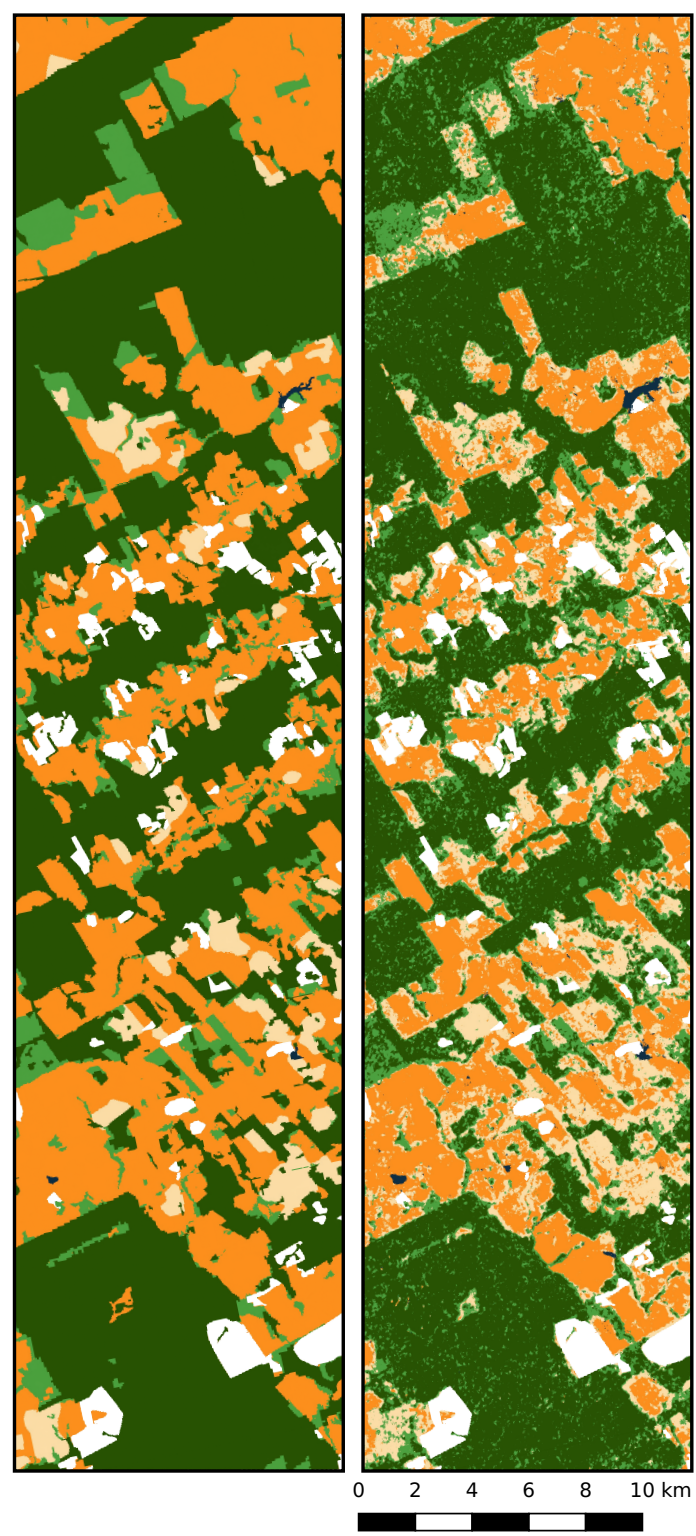

Figure 6. Final classification product using multi-temporal, multi-frequency imagery compared to TerraClass reference data set. Note that inconsistent classes from the TerraClass dataset are masked out white.

Table 3. Population error matrix derived from classification of the full dataset and TerraClass reference data. Numbers reflect area adjusted percentages as introduced by Equation (1).

\begin{tabular}{lccccccc}
\hline & \multicolumn{7}{c}{ Reference } \\
\hline Classification & $\mathbf{1}$ & $\mathbf{2}$ & $\mathbf{3}$ & $\mathbf{4}$ & $\mathbf{5}$ & Sum & User's Accuracy \\
\hline 1 Primary Forest & $\mathbf{3 9 . 2 7}$ & 1.94 & 0.27 & 2.04 & 0.00 & 43.51 & 90.26 \\
2 Clean Pasture & 1.13 & $\mathbf{2 4 . 0 5}$ & 1.00 & 0.79 & 0.00 & 27.01 & 89.04 \\
3 Shrubby Pasture & 2.23 & 8.42 & $\mathbf{2 . 5 5}$ & 1.25 & 0.00 & 14.46 & 17.64 \\
4 Secondary Vegetation & 7.32 & 3.44 & 0.57 & $\mathbf{3 . 3 3}$ & 0.00 & 14.66 & 22.72 \\
5 Water & 0.04 & 0.21 & 0.01 & 0.02 & $\mathbf{0 . 0 8}$ & 0.36 & 22.22 \\
\hline Sum & 49.99 & 38.07 & 4.44 & 7.43 & 0.08 & 100 & \\
Producer's Accuracy & 78.56 & 63.17 & 57.43 & 44.81 & 100 & & \\
\hline
\end{tabular}




\section{Discussion}

As expected, the combination of multitemporal SAR data from different sensors sets proves useful for tropical land cover mapping. Obtained overall accuracies are higher than those achieved by single source data sets. The results clearly underline the relevance of the AL2 scenes, which yield the highest accuracies when compared to the TSX and RS2 data. This reflects the general consensus in literature, which acknowledges systems of longer wavelengths to be favorable concerning vegetation mapping $[25,47,54]$. AL2 is in particular the most adequate sensor for mono-frequent, mono-temporal classifications (Table 2) and, thus, seems sufficient when data availability is limited. A visual interpretation of the classification results confirms these findings (Figure 3). While Primary Forest and Secondary Vegetation tend to be less confused when using AL2 data, Secondary Vegetation is overestimated by TSX data. However, the positive effects of the high spatial resolution of TSX are clearly visible in the classification results. Edges along individual land cover types, e.g., the nearly rectangular pasture area, can be more clearly identified, while these boundaries appear blurred in the results achieved by RS2 and AL2 data. Moreover, the differentiation between managed and unmanaged areas is challenging for RS2 data, indicated by many patches of Primary Forest that are misclassified as Pasture. While any individual AL2 acquisition outperforms any RS2 as well as any TSX scene, the wrapper selects a TSX at the second iteration. Even the combination of one AL2 scene with a RS2 scene outperforms the classification results achieved by two AL2 scenes. The positive impact of combining multi-frequency data is further underlined by the third iteration of the wrapper. After integration of the first TSX scene at the second iteration, RS2 images lead to the strongest gains in accuracy, despite their weak initial performances. Hence, acquisitions of each sensor are utilized after just three iterations, underlining the potential of including multi-frequency SAR images for land cover mapping. This is in accordance with previous findings, e.g., by Naidoo et al. [47], who also document slight advantages of multi-frequency integration, yet remark on limited gains over L-band data alone for the purpose of biomass mapping.

After scenes of each sensor are integrated, gains in accuracy are receding rapidly. Additionally, it appears that the advantages of AL2 and TSX do not appear to transfer over to the subsequent iterations. Two times RS2 is chosen over AL2 and TSX (iterations 5 and 6), yet all scenes are performing very similarly as they yield a low variance in accuracy. The range of accuracies for the fifth iteration is already very narrow at $0.13 \mathrm{pp}$., and the gain of the fifth over fourth iteration is only at $0.27 \mathrm{pp}$. The population error matrix (Table 3) reflects the stratified sampling, with Shrubby Pasture and Water being overrepresented. The confusion between pasture areas deserves special attention in particular. While TerraClass products imply Clean Pasture and Shrubby Pasture to be stable over the years, we observe these classes to be very ambiguous. Inspection of the land cover maps shows the confusion of Pasture classes to often affect continuous areas that are misattributed (see Figure 3). Counterintuitively, we observe that Shrubby Pasture areas do not necessarily align with regions of increased backscatter. Reasons might be a high inner-class and intra-annual variance, seasonality overall, and possibly limitations concerning the interpretation of the two classes in the TerraClass dataset. Intra-annual variance is of particular interest, as the underlying SAR acquisitions are spread over the entire dry period, which in general also coincide with a decrease of shrubby, in favor of clean pasture [59]. Since these effects are present in the training as well as testing data, classification outcomes are affected to a certain degree. In particular, results of classifications that might be capable of separating the pasture types might be lessened, as the inherent variance could introduce non-recoverable confusion. This is also indicated by the lower confusion between Secondary Vegetation and Shrubby Pasture, which can be separated more reliably despite being very similar in visual appearance. In contrast, the confusion between Secondary Vegetation and Primary Forest appears to be more random and is distributed spatially, while individual small regions of Secondary Vegetation can generally be made out. Consequently, these classes might not be classified well even with available L-band imagery, which might be a direct consequence of the saturation of L-band in environments of high biomass $[69,70]$. Comparing the reference classification as shown by Figure 3 with the classification outcomes of the first iteration, 
TSX shows the potential to improve on the Pasture classes. However, these potentials are not reflected after integration of TSX scenes into the fused product (Figure 4).

Given its low resolution and all of the data being upsampled to TSX' spatial resolution, RS2 should be affected more positively by spatial autocorrelation than the other sensors, yet these effects appear to be miniscule. Additional tests also show a very limited effect of the chosen upsampling strategy with regard to the confidences of accuracies, which remains on a comparably high level even when just an eighth of the testing data is utilized.

Some factors are not considered in this study. Data is obtained in the standard operation modes of the examined sensors. While other acquisition modes might lead to more similar data sets regarding spatial resolution, spatial extent, or polarization, the authors had no influence in e.g., the acquisition of AL2 data, which is HH-HV polarized. A potential consequence could be a higher gain in accuracy at the second iteration for non-AL2 scenes, as not only the benefits of including an additional wavelength are factored in, but also the benefits of including an additional polarization. As 45 models have to be trained using 15,000 samples with up to 198 features, and the classification of entire images has to be conducted to estimate area adjusted accuracies, the study is effortlessly handled by a common desktop PC (i7-3770 @ 3.40 Ghz). In case of accessible multi-frequency SAR data, it is possible to utilize current open source packages, i.e., ESA's Snap, GDAL, Python, Q-GIS, to conduct powerful land cover analyses using a combination of standard workflows. Limitations can be caused by a mixture of ascending and descending passes, as well as inconsistent looking directions. Having considered this and not aiming for interferometric accuracy, coregistration of images could be achieved without manual adjustments even at varying looking angles. Reference data was mainly collected using alternative sources, which we highly recommend in any case for conducting land cover analyses on SAR data.

\section{Conclusions}

In the presented study, the contribution of multi-frequency SAR data to topical land cover mapping was analyzed. However, a complementary integration of additional X-and C-band images yield higher accuracies when compared to the classification of multi-temporal AL2 scenes alone. Moreover, the results show that TSX outperforms RS2 for individual classifications in terms of accuracy. Given a set of multi-frequency imagery, the integration of additional scenes leads to an increase in accuracy, yet this effect is weakened with a growing number of scenes. In addition, advantages of adding multiple AL2 over TSX or RS2 scenes do not exist if an AL2 scene is integrated already. For this reason, when adding scenes to a dataset that is already multi-frequency, advantages of adding certain frequencies are also negligible. Finally, we show that a wrapper can be implemented effortlessly and is very applicable for the identification of most relevant acquisitions. Generally, the results show that the use of multisensor SAR data is worthwhile and the classification accuracy is significantly increased by such data sets. Moreover, classifiers such as Random Forest prove useful in various studies for handling large and multisource data sets. This is particularly important with respect to recent and planned missions with increased revisit times and better spatial resolutions such as Sentinel-1 (C-band), the NASA-ISRO Synthetic Aperture Radar (NISAR, L/S-band), or High Resolution Wide Swath (HRWS, X-band).

Acknowledgments: The study was carried out as part of the SenseCarbon research project funded by DLR/BMWi (50 EE 1255). SenseCarbon is part of GFOI-R\&D (BRA-2). TerraSAR-X data was acquired as part of the SCIENCE PHASE AO (MTH2422), RADARSAT-2 through SOAR-EI 5175, and ALOS-2 through the 6th Research Announcement for ALOS-2 (PI-3176). We thank the countless developers behind the freely accessible software utilized in this study (i.e., Python, GDAL, S1TBX, and Q-GIS).

Author Contributions: Ron Hagensieker was responsible for writing the article and conducting the described study. Björn Waske supervised the work and contributed to the writing process.

Conflicts of Interest: The authors declare no conflicts of interest. 


\section{References}

1. Hooper, D.U.; Adair, E.C.; Cardinale, B.J.; Byrnes, J.E.; Hungate, B.A.; Matulich, K.L.; Gonzalez, A.; Duffy, J.E.; Gamfeldt, L.; OConnor, M.I. A global synthesis reveals biodiversity loss as a major driver of ecosystem change. Nature 2012, 486, 105-108.

2. Bustamante, M.M.; Nobre, C.A.; Smeraldi, R.; Aguiar, A.P.; Barioni, L.G.; Ferreira, L.G.; Longo, K.; May, P.; Pinto, A.S.; Ometto, J.P. Estimating greenhouse gas emissions from cattle raising in Brazil. Clim. Chang. 2012, 115, 559-577.

3. Foley, J.A. Global Consequences of Land Use. Science 2005, 309, 570-574.

4. Sombroek, W. Spatial and Temporal Patterns of Amazon Rainfall. AMBIO 2001, 30, 388-396.

5. Lambin, E.F.; Turner, B.; Geist, H.J.; Agbola, S.B.; Angelsen, A.; Bruce, J.W.; Coomes, O.T.; Dirzo, R.; Fischer, G.; Folke, C.; et al. The causes of land-use and land-cover change: Moving beyond the myths. Glob. Environ. Chang. 2001, 11, 261-269.

6. Beuchle, R.; Grecchi, R.C.; Shimabukuro, Y.E.; Seliger, R.; Eva, H.D.; Sano, E.; Achard, F. Land cover changes in the Brazilian Cerrado and Caatinga biomes from 1990 to 2010 based on a systematic remote sensing sampling approach. Appl. Geogr. 2015, 58, 116-127.

7. Zhu, Z.; Woodcock, C.E. Continuous change detection and classification of land cover using all available Landsat data. Remote Sens. Environ. 2014, 144, 152-171.

8. Reiche, J.; Verbesselt, J.; Hoekman, D.; Herold, M. Fusing Landsat and SAR time series to detect deforestation in the tropics. Remote Sens. Environ. 2015, 156, 276-293.

9. Liu, D.; Song, K.; Townshend, J.R.; Gong, P. Using local transition probability models in Markov random fields for forest change detection. Remote Sens. Environ. 2008, 112, 2222-2231.

10. Müller, H.; Griffiths, P.; Hostert, P. Long-term deforestation dynamics in the Brazilian Amazon-Uncovering historic frontier development along the Cuiabá-Santarém highway. Int. J. Appl. Earth Obs. Geoinf. 2016, 44, 61-69.

11. Tewkesbury, A.P.; Comber, A.J.; Tate, N.J.; Lamb, A.; Fisher, P.F. A critical synthesis of remotely sensed optical image change detection techniques. Remote Sens. Environ. 2015, 160,1-14.

12. Barretto, A.G.; Berndes, G.; Sparovek, G.; Wirsenius, S. Agricultural intensification in Brazil and its effects on land-use patterns: An analysis of the 1975-2006 period. Glob. Chang. Biol. 2013, 19, 1804-1815.

13. Nepstad, D.; McGrath, D.; Stickler, C.; Alencar, A.; Azevedo, A.; Swette, B.; Bezerra, T.; DiGiano, M.; Shimada, J.; da Motta, R.S.; et al. Slowing Amazon deforestation through public policy and interventions in beef and soy supply chains. Science 2014, 344, 1118-1123.

14. Soares-Filho, B.; Rajão, R.; Macedo, M.; Carneiro, A.; Costa, W.; Coe, M.; Rodrigues, H.; Alencar, A. Cracking Brazil's Forest Code. Science 2014, 344, 363-364.

15. Reynolds, J.; Wesson, K.; Desbiez, A.; Ochoa-Quintero, J.; Leimgruber, P. Using Remote Sensing and Random Forest to Assess the Conservation Status of Critical Cerrado Habitats in Mato Grosso do Sul, Brazil. Land 2016, 5, 12, doi:10.3390/land5020012.

16. Carreiras, J.M.B.; Jones, J.; Lucas, R.M.; Gabriel, C. Land Use and Land Cover Change Dynamics across the Brazilian Amazon: Insights from Extensive Time-Series Analysis of Remote Sensing Data. PLoS ONE 2014, 9, e104144.

17. Hansen, M.C.; Potapov, P.V.; Moore, R.; Hancher, M.; Turubanova, S.A.; Tyukavina, A.; Thau, D.; Stehman, S.V.; Goetz, S.J.; Loveland, T.R.; et al. High-Resolution Global Maps of 21st-Century Forest Cover Change. Science 2013, 342, 850-853.

18. Asner, G.P. Cloud cover in Landsat observations of the Brazilian Amazon. Int. J. Remote Sens. 2001, $22,3855-3862$.

19. Ouchi, K. Recent Trend and Advance of Synthetic Aperture Radar with Selected Topics. Remote Sens. 2013, 5, 716-807.

20. Moreira, A.; Pratstiraola, P.; Younis, M.; Krieger, G.; Hajnsek, I.; Papathanassiou, K.P. A Tutorial on Synthetic Aperture Radar. IEEE Geosci. Remote Sens. Mag. 2013, 1, 6-43.

21. Aschbacher, J.; Milagro-Pérez, M.P. The European Earth monitoring (GMES) programme: Status and perspectives. Remote Sens. Environ. 2012, 120, 3-8. 
22. McNairn, H.; Champagne, C.; Shang, J.; Holmstrom, D.; Reichert, G. Integration of optical and Synthetic Aperture Radar (SAR) imagery for delivering operational annual crop inventories. ISPRS J. Photogramm. Remote Sens. 2009, 64, 434-449.

23. Wulder, M.A.; Masek, J.G.; Cohen, W.B.; Loveland, T.R.; Woodcock, C.E. Opening the archive: How free data has enabled the science and monitoring promise of Landsat. Remote Sens. Environ. 2012, 122, 2-10.

24. Stofan, E.; Evans, D.; Schmullius, C.; Holt, B.; Plaut, J.; van Zyl, J.; Wall, S.; Way, J. Overview of results of Spaceborne Imaging Radar-C, X-Band Synthetic Aperture Radar (SIR-C/X-SAR). IEEE Trans. Geosci. Remote Sens. 1995, 33, 817-828.

25. Schmullius, C.C.; Evans, D.L. Review article Synthetic aperture radar (SAR) frequency and polarization requirements for applications in ecology, geology, hydrology, and oceanography: A tabular status quo after SIR-C/X-SAR. Int. J. Remote Sens. 1997, 18, 2713-2722.

26. Schlund, M.; von Poncet, F.; Hoekman, D.H.; Kuntz, S.; Schmullius, C. Importance of bistatic SAR features from TanDEM-X for forest mapping and monitoring. Remote Sens. Environ. 2014, 151, 16-26.

27. Schuster, C.; Schmidt, T.; Conrad, C.; Kleinschmit, B.; Förster, M. Grassland habitat mapping by intra-annual time series analysis-Comparison of RapidEye and TerraSAR-X satellite data. Int. J. Appl. Earth Obs. Geoinf. 2015, 34, 25-34.

28. Sonobe, R.; Tani, H.; Wang, X.; Kobayashi, N.; Shimamura, H. Random forest classification of crop type using multi-temporal TerraSAR-X dual-polarimetric data. Remote Sens. Lett. 2014, 5, 157-164.

29. Ban, Y.; Jacob, A.; Gamba, P. Spaceborne SAR data for global urban mapping at $30 \mathrm{~m}$ resolution using a robust urban extractor. ISPRS J. Photogramm. Remote Sens. 2015, 103, 28-37.

30. Du, P.; Samat, A.; Waske, B.; Liu, S.; Li, Z. Random Forest and Rotation Forest for fully polarized SAR image classification using polarimetric and spatial features. ISPRS J. Photogramm. Remote Sens. 2015, 105, 38-53.

31. Rakwatin, P.; Longépé, N.; Isoguchi, O.; Shimada, M.; Uryu, Y.; Takeuchi, W. Using multiscale texture information from ALOS PALSAR to map tropical forest. Int. J. Remote Sens. 2012, 33, 7727-7746.

32. Almeida-Filho, R.; Shimabukuro, Y.E.; Rosenqvist, A.; Sanchez, G.A. Using dual-polarized ALOS PALSAR data for detecting new fronts of deforestation in the Brazilian Amazônia. Int. J. Remote Sens. 2009, 30, 3735-3743.

33. Kurvonen, L.; Pulliainen, J.; Hallikainen, M. Retrieval of biomass in boreal forests from multitemporal ERS-1 and JERS-1 SAR images. IEEE Trans. Geosci. Remote Sens. 1999, 37, 198-205.

34. Nelson, M.D.; Ward, K.T.; Bauer, M.E. Forest-Cover-Type Separation Using RADARSAT-1 Synthetic Aperture Radar Imagery; U.S. Department of Agriculture: Washington, DC, USA, 2009.

35. Zhang, F.; Xu, M.; Xie, C.; Xia, Z.; Li, K.; Wang, X. Forest and deforestation identification based on multitemporal polarimetric RADARSAT-2 images in Southwestern China. J. Appl. Remote Sens. 2012, $6,063527$.

36. Taubenböck, H.; Felbier, A.; Esch, T.; Roth, A.; Dech, S. Pixel-based classification algorithm for mapping urban footprints from radar data: A case study for RADARSAT-2. Can. J. Remote Sens. 2012, 38, 211-222.

37. Shao, Y.; Fan, X.; Liu, H.; Xiao, J.; Ross, S.; Brisco, B.; Brown, R.; Staples, G. Rice monitoring and production estimation using multitemporal RADARSAT. Remote Sens. Environ. 2001, 76, 310-325.

38. Waske, B.; Braun, M. Classifier ensembles for land cover mapping using multitemporal SAR imagery. ISPRS J. Photogramm. Remote Sens. 2009, 64, 450-457.

39. Stefanski, J.; Chaskovskyy, O.; Waske, B. Mapping and monitoring of land use changes in post-Soviet western Ukraine using remote sensing data. Appl. Geogr. 2014, 55, 155-164.

40. Jin, H.; Mountrakis, G.; Stehman, S.V. Assessing integration of intensity, polarimetric scattering, interferometric coherence and spatial texture metrics in PALSAR-derived land cover classification. ISPRS J. Photogramm. Remote Sens. 2014, 98, 70-84.

41. Cutler, M.; Boyd, D.; Foody, G.; Vetrivel, A. Estimating tropical forest biomass with a combination of SAR image texture and Landsat TM data: An assessment of predictions between regions. ISPRS J. Photogramm. Remote Sens. 2012, 70, 66-77.

42. Voisin, A.; Krylov, V.A.; Moser, G.; Serpico, S.B.; Zerubia, J. Classification of very high resolution SAR images of urban areas using copulas and texture in a hierarchical Markov random field model. IEEE Geosci. Remote Sens. Lett. 2013, 10, 96-100.

43. Waske, B.; van der Linden, S. Classifying multilevel imagery from SAR and optical sensors by decision fusion. IEEE Trans. Geosci. Remote Sens. 2008, 46, 1457-1466. 
44. Li, G.; Lu, D.; Moran, E.; Dutra, L.; Batistella, M. A comparative analysis of ALOS PALSAR L-band and RADARSAT-2 C-band data for land-cover classification in a tropical moist region. ISPRS J. Photogramm. Remote Sens. 2012, 70, 26-38.

45. Wang, X.; Ge, L.; Li, X. Pasture Monitoring Using SAR with COSMO-SkyMed, ENVISAT ASAR, and ALOS PALSAR in Otway, Australia. Remote Sens. 2013, 5, 3611-3636.

46. Naidoo, L.; Mathieu, R.; Main, R.; Kleynhans, W.; Wessels, K.; Asner, G.P.; Leblon, B. The assessment of data mining algorithms for modelling Savannah Woody cover using multi-frequency (X-, C- and L-band) synthetic aperture radar (SAR) datasets. In Proceedings of the 2014 IEEE Geoscience and Remote Sensing Symposium, Quebec City, QC, Canada, 13-18 July 2014.

47. Naidoo, L.; Mathieu, R.; Main, R.; Kleynhans, W.; Wessels, K.; Asner, G.; Leblon, B. Savannah woody structure modelling and mapping using multi-frequency (X-, C- and L-band) Synthetic Aperture Radar data. ISPRS J. Photogramm. Remote Sens. 2015, 105, 234-250.

48. Baghdadi, N.; Boyer, N.; Todoroff, P.; El Hajj, M.; Bégué, A. Potential of SAR sensors TerraSAR-X, ASAR/ENVISAT and PALSAR/ALOS for monitoring sugarcane crops on Reunion Island. Remote Sens. Environ. 2009, 113, 1724-1738.

49. Kohavi, R.; John, G.H. Wrappers for feature subset selection. Artif. Intell. 1997, 97, 273-324.

50. Fearnside, P.M. Brazil's Cuiabá- Santarém (BR-163) Highway: The Environmental Cost of Paving a Soybean Corridor Through the Amazon. Environ. Manag. 2007, 39, 601-614.

51. Coy, M.; Klingler, M. Frentes pioneiras em transformação: O eixo da BR-163 e os desafios socioambientais. Territ. Front. 2014, 7, 1-26.

52. Suzuki, S.; Osawa, Y.; Hatooka, Y.; Kankaku, Y.; Watanabe, T. Overview of Japan's Advanced Land Observing Satellite-2 mission. In Proceedings of the Sensors, Systems, and Next-Generation Satellites XIII, Berlin, Germany, 31 August-3 September 2009.

53. Morena, L.; James, K.; Beck, J. An introduction to the RADARSAT-2 mission. Can. J. Remote Sens. 2004, 30, 221-234.

54. Sarker, M.L.R.; Nichol, J.; Iz, H.B.; Ahmad, B.; Rahman, A.A. Forest Biomass Estimation Using Texture Measurements of High-Resolution Dual-Polarization C-Band SAR Data. IEEE Trans. Geosci. Remote Sens. 2013, 51, 3371-3384.

55. Werninghaus, R. TerraSAR-X mission. In Proceedings of the SAR Image Analysis, Modeling, and Techniques VI, Barcelona, Spain, 12 January 2004.

56. De Almeida, C.A.; Coutinho, A.C.; Esquerdo, J.C.D.M.; Adami, M.; Venturieri, A.; Diniz, C.G.; Dessay, N.; Durieux, L.; Gomes, A.R. High spatial resolution land use and land cover mapping of the Brazilian Legal Amazon in 2008 using Landsat-5/TM and MODIS data. Acta Amaz. 2016, 46, 291-302.

57. Instituto Nacional de Pesquisas Espaciais (INPE). Projeto PRODES-Monitoramento da Floresta Amazonica Brasileira por Satelite; Instituto Nacional de Pesquisas Espaciais: São José dos Campos, Brazil, 2015.

58. Hansen, M.; Shimabukuro, Y.; Potapov, P.; Pittmann, K. Comparing annual MODIS and PRODES forest cover change data for advancing monitoring of Brazilian forest cover. Remote Sens. Environ. 2008, 112, 3784-3793.

59. Hagensieker, R.; Roscher, R.; Rosentreter, J.; Jakimow, B.; Waske, B. Tropical land use land cover mapping in Pará (Brazil) using discriminative Markov random fields and multi-temporal TerraSAR-X data. Int. J. Appl. Earth Obs. Geoinf. 2017, 63, 244-256.

60. Small, D. Flattening Gamma: Radiometric Terrain Correction for SAR Imagery. IEEE Trans. Geosci. Remote Sens. 2011, 49, 3081-3093.

61. Haralick, R.M.; Shanmugam, K.; Dinstein, I.H. Textural features for image classification. IEEE Trans. Syst. Man Cybern. 1973, 610-621, doi:10.1109/TSMC.1973.4309314.

62. Baraldi, A.; Parmiggiani, F. A refined gamma MAP SAR speckle filter with improved geometrical adaptivity. IEEE Trans. Geosci. Remote Sens. 1995, 33, 1245-1257.

63. Breiman, L. Random forests. Mach. Learn. 2001, 45, 5-32.

64. Belgiu, M.; Drăguţ, L. Random forest in remote sensing: A review of applications and future directions. ISPRS J. Photogramm. Remote Sens. 2016, 114, 24-31.

65. Chan, J.C.W.; Paelinckx, D. Evaluation of Random Forest and Adaboost tree-based ensemble classification and spectral band selection for ecotope mapping using airborne hyperspectral imagery. Remote Sens. Environ. 2008, 112, 2999-3011. 
66. Waske, B.; van der Linden, S.; Benediktsson, J.; Rabe, A.; Hostert, P. Impact of different morphological profiles on the classification accuracy of urban hyperspectral data. In Proceedings of the 2009 First Workshop on Hyperspectral Image and Signal Processing: Evolution in Remote Sensing, Grenoble, France, 26-28 August 2009.

67. Maghsoudi, Y.; Collins, M.J.; Leckie, D.G. Radarsat-2 Polarimetric SAR Data for Boreal Forest Classification Using SVM and a Wrapper Feature Selector. IEEE J. Sel. Top. Appl. Earth Obs. Remote Sens. 2013, 6, 1531-1538.

68. Olofsson, P.; Foody, G.M.; Herold, M.; Stehman, S.V.; Woodcock, C.E.; Wulder, M.A. Good practices for estimating area and assessing accuracy of land change. Remote Sens. Environ. 2014, 148, 42-57.

69. Yu, Y.; Saatchi, S. Sensitivity of L-Band SAR Backscatter to Aboveground Biomass of Global Forests. Remote Sens. 2016, 8, 522, doi:10.3390/rs8060522.

70. Mermoz, S.; Réjou-Méchain, M.; Villard, L.; Le Toan, T.; Rossi, V.; Gourlet-Fleury, S. Decrease of L-band SAR backscatter with biomass of dense forests. Remote Sens. Environ. 2015, 159, 307-317.

(C) 2018 by the authors. Licensee MDPI, Basel, Switzerland. This article is an open access article distributed under the terms and conditions of the Creative Commons Attribution (CC BY) license (http:/ / creativecommons.org/licenses/by/4.0/). 